\title{
Aktif Öğrenmeye İlişkin Lisansüstü Tezlerin Yapısal İncelenmesi
}

\section{An Examination of Postgraduate Theses Written About Active Learning}

\section{Duygu GÜR ERDOǦAN*}

Öz. Bu çalışmanın amacı aktif öğrenmeye yönelik uygulamaların nasıl yapıldığına dair genel bir tablo çıkartmak adına aktif öğrenme konusunu irdeleyen lisansüstü tezlerin yapısal olarak incelenmesidir. Bu amaçla araştırma tarama modelinde desenlenmiş olup veriler doküman analizi yoluyla incelenmiştir. Çalışmanın evrenini aktif öğrenme konusunu içeren Yüksek Öğretim Kurumu (YÖK)'nun internet sitesinde yayınlanmış tüm tezler oluşturmaktadır. Araştırmada tez başlıklarında ya da anahtar kelimelerinde aktif öğrenme aranmışve 92 teze ulaşılmıştır. Araştırmada elde edilen veriler doküman analizinde yer alan kodlama yöntemine göre kodlanmıştır. Sekiz alt başlık (yayın yılı, yayın türü, araştırma yöntemleri, araştırma modelleri, örneklem türü, evren/örneklem/ çalışma grubu tanımlaması, araştırmaların değişkenleri ve veri toplama araçları) altında araştırmalara ait çalışma kimliği ve çalışma içeriği ile ilgili bilgiler yer almaktadır. Araştırma sonunda aktif öğrenme konusunu içeren tez çalışmalarının en çok 2010 yılında yapıldığı, tezlerde nicel yöntemlerin ve deneysel modelin daha ağırlıklı kullanıldığı, en fazla kullanılan örnekleme türünün amaçlı örnekleme ve en fazla kullanılan veri toplama aracının başarı testi olduğu bulunmuştur.

Anahtar Kelimeler: Aktif öğrenme, öğrenme yöntemi, lisansüstü, tez, doküman analizi.

\begin{abstract}
The aim of this study is to constructionally analyse postgraduate theses on active learning subject in order to create a general overview about how applications oriented towards active learning are performed. In the light of this aim, the study was figured in survey model and the data were analysed via document analysis method. The population of the study is composed of all the theses published on Council of Higher Education (YÖK) website which include the subject of active learning. Active learning was searched in the theses' titles or in the keywords and 92 theses were found. The data obtained in the study were coded according to the coding method in the document analysis. 8 sub headings (publish year, publish type, research methods, research models, sample type, population/sample/study group specification, research variables and data collection tools) offer data related to work group identification and work content. In the conclusion of the study, it was found that theses including active learning subject were performed in 2010 most, quantitative methods and empirical model were used more, the most common sampling type was purposeful sampling and the most common data collection tool was achievement test.
\end{abstract}

Keywords: Active learning, learning method, postgraduate, thesis, qualitative document review.

\section{Toplumsal Mesaj.}

Çalışmada amaç aktif öğrenme ile ilgili yapılan tezlerin yönelimlerine bakarak aktif öğrenmenin günümüz eğitim sistemi içerisindeki işlevselliğini ve görünürlüğünü ortaya çıkarmaktır. Bu bağlamda yapılan çalışma tezleri yapısal açıdan incelemiştir.

Public Interest Statement.

The aim of this study is to find out the functionality and visibility of active learning in today's educational system by checking the orientations of the theses related to active learning. In this context, the study analysed the theses constructionally.

\footnotetext{
*Yrd. Doç. Dr., Sakarya Üniversitesi Ĕgitim Fakültesi, Eğitim Programları ve Öğretimi Anabilim Dalı, dgur@sakarya.edu.tr

${ }^{* *}$ Yrd. Doç. Dr., Sakarya Üniversitesi Eğitim Fakültesi, Eğitimde Ölçme ve Değerlendirme Anabilim Dalı, guldenk@sakarya.edu.tr

${ }^{* * *}$ Yrd. Doç. Dr., Sakarya Üniversitesi Eğitim Fakültesi, Bilgisayar ve Öğretim Teknolojileri Eğitimi Anabilim Dalı, ocanan@sakarya.edu.tr
} 


\section{GiRiş}

Öğrenmede değişen eğilimlerle birlikte artık öğrenenin öğrenme merkezinde olduğu, öğrenenin kendi öğrenme sorumluluğunu üstlendiği yaklaşımlar ön plana çıkmaktadır. Özellikle sınıf içi ve sınıf dışı öğrenme etkinlikleri kapsamında öğrencinin yaparak yaşayarak öğrenmesini sağlayan yöntem ve tekniklerin kullanılmasına ilişkin bir yönelim göze çarpmaktadır. Artık gelişen ve değişen bilgi dünyasında tek bir doğru bilgi yoktur ve bilgi kaynağı tek değildir. Mentiş-Taş, (2005)'ın da ifade ettiği gibi "günümüzün en geçerli bilgisi bile bu değişim ve yenilenme sürecinde hızla geçerliliğini yitirmektedir bu nedenle, bilgiye sahip olmak, bilgiyi elinde tutmak bilgiyi aktarıcı rolü üstlenmek anlamlı değildir". Bu yüzden öğretmenin merkezde ve aktif olduğu yöntemlerden öğrencinin merkezde ve aktif olduğu yöntemlere doğru bir geçişin olduğu net bir şekilde hissedilmektedir. Özellikle son zamanlarda, eğitim araştırmalarına yönelik yapılan araştırmalar ve uygulamalarda öğretmen merkezli yaklaşımların yerine öğrenci merkezli yaklaşımlar daha fazla önem ve ă̆ırlık kazanmaktadır (Taşpınar, 1998:46). Aslında eğitim, öğretim ve öğrenmenin zaten doğasında olan aktiflik, öğrenci merkezlilik, probleme dayalılık gibi özellikler, eğitimde en son yenilikler diye (Ünal, 1999) aktif öğrenme olarak karşımıza çıkmaktadır. NRC (1996) bütün eğitim reformlarının öğretim süreçlerine ilişkin ana felsefe anlayışının, ağırlıklı olarak öğrenci merkezli olan aktif öğretim yaklaşımlarının yer alması olduğu ifadesine yer verirken, MEB 2004-2005 öğretim yılında pilot uygulamayla düzenlediği öğretim programlarını yapılandırmacı öğrenme kuramına dayandırarak aktif öğrenme-öğretme yaklaşımlarına programda yer vermiştir. Son yıllarda pek çok ülkede oldukça ilgi gören aktif öğrenme öğrenciyi öğrenmenin merkezine alan, öğrencinin pasif ve gözlemci konumundan çıkıp öğrenme olayının içinde yer aldığı ve aktif olduğu bir öğrenme durumu (Ün-Açıkgöz, 2014; Kalem ve Fer, 2003) şeklinde ifade edilmektedir. Öğrenenin öğrenmesine ilişkin bakış açısının öğrenme öğretme süreçlerine yansıması (Koç, 2011) ve öğrencinin kendi öğrenme süreci hakkında söz sahibi olduğu bir öğrenme ya da öğrencinin kendi bilişsel yetilerini zorlayarak yapılan öğrenme şekli (Ünal, 1999) olarak da ifade edilebilen aktif öğrenme için öğrenmenin öğrencinin kendi sorumluluğunda olan bir öğrenme şekli olduğu söylenebilir.

Dewey'in problem çözme, Piaget'in oluşturmacılık, Bruner'in öğrenmeyi keşfetme ve Vygotsky'nin sosyal öğrenme kuramına dayanan (Çelik, Şenocak, Bayrakçeken, Taşkesenligil ve Doymuş, 2005) aktif öğrenme öğrencilerin bir şeyler yapıyor olmasını ve yaptıkları şeyler üzerine düşünmelerini ve bilginin keşfedilmesinde anlamlı öğrenci katılımı için tasarlanmış öğretim tekniklerini içerir (Bonwell ve Eison, 1991; Lantis, Kille ve Krain, 2010). Öğrenciler aktif olarak bilginin yaratılmasılyla ilgilidirler ve öğrenenler için önemli şeylere odaklanılır (Adams ve Burns, 1999). Kalem ve Fer (2003), tarafından da ifade edildiği gibi "aktif öğrenmede geleneksel öğretimin tersine öğrenenlerin sosyal, entelektüel, kültürel, bireysel ve fiziksel kapasitelerini kullanmalarına olanak sağlanmaktadır." Öğrenci aktif öğrenme ile bir yandan öğrenme süreciyle ilgili kararlar alırken diğer yandan kendi istek ve gayretiyle tüm bilişsel süreçlerini seferber eder (Simons, 1997: 19; Akt: Ünal, 1999). Sivan ve ark. (2000) "aktif öğrenme yaklaşımının, öğrencilerin başarılarını artırmanın ötesinde, öğrencilerde merak duygusunun oluşmasını; bilgiyi kullanma ve geliştirme, bağımsız öğrenme becerilerini geliştirme ve gelecek planlamalar yapabilme becerilerini artırdığını dile getirmiştir" (Akt: Aydede ve Matyar, 2009). Aktif öğretim ve öğrenme yaklaşımları öğrencileri karmaşık ve tartışmalı konular üzerine risk almak ve görüşlerini dile getirmek için zorlayarak güçlü ve etkili öğrenme ortamları yaratabilir (Lamy 2000). Literatürde yapılan pek çok çalışma (Newmann 1991; Wilke, 2003; Zavrak, 2003; Fies, 2005; Aydede, 2006; Aydede ve Matyar, 2009, Simelane ve Dimpe, 2011, Bozyiğit, Onan, Özçınar ve Erdem, 2014) aktif öğrenmenin öğrenci başarısı, bilgisi, becerisi, ilgisini, tutumunu arttırarak öğrenmeyi daha kolay, anlamlı ve etkili hale getirdiğini göstermektedir. Ayrıca aktif öğrenmenin okuduğunu anlama ve eleştirel düşünme (Koç, 2011), öğrencinin kendi kendine öğrenme becerisini geliştirme (Aydede ve Kesercioğlu, 2012), öğrenme- öğretme ve iletişim sürecine (Kalem ve Fer, 2003), öğrencinin bağımsız öğrenme becerisine (Sivan, Leung, Woon ve Kember, 2010), olumlu etkisi olduğu görülmektedir. 
Aktif öğrenme yaklaşımlarının öğrenme ve öğrenme - öğretme süreci üzerindeki gözlenen bu olumlu etkilerinden dolayı aktif öğrenme ile ilgili yapılmış pek çok çalışma ve tez bulunmaktadır. Özellikle bu alanla ilgili son yıllarda, birçok farklı enstitü ve fakülte bünyesinde yapılan tez çalışmalarına rastlanmaktadır. Ancak alan yazında, aktif öğrenme öğrenmeyle ilgili lisansüstü tez çalışmalarını analiz ederek derleyen, bir araya getirip ortak bir çerçeveden bakma olanağı sunan bir çalışma bulunmamaktadır. Lisansüstü çalışmalarda aktif öğrenme konusunda nasıl çalışmalar yapıldığına ve bu çalışmalarda özellikle nelerin irdelendiğine dair genel bir çerçeve belirlemek önemli görülmektedir. Aktif öğrenme tezleri ile ilgili bir yapısal inceleme çalışmasının bu gereksinimi giderebileceği, bu konudaki boşlukları belirleyerek alana katkı getirebileceği düşünülmektedir. Bu amaç doğrultusunda bu çalışmada aktif öğrenmeye ilişkin kapsamlı olarak yapılmış lisansüstü tezler, ülkemizde aktif öğrenmeye yönelik uygulamaların yapılış biçimi araştırmanın temel amacı olarak belirlenmiştir.

\section{YÖNTEM}

Bu çalışmada aktif öğrenmeye yönelik uygulamaların nasıl yapıldığına dair genel bir tablo çıkartmak adına aktif öğrenme konusunu irdeleyen yüksek lisans ve doktora tezlerinin yapısal olarak incelenmesi amaçlanmıştır. Bu amaçla araştırma tarama modelinde desenlenmiş olup veriler araştııılan olay ya da olgular hakkında yazılı bilgi içeren dokümanların ayrıntılı biçimde analiz edilmesini sağlayan doküman analizi (Yıldırım ve Şimşek, 2005) yoluyla incelenmiştir. Araştırma kapsamında incelenen konuyla ilgili olgu ve olaylar hakkında bilgi içeren yazılı belgelerin analiz edilmesiyle veri sağlanmasına doküman incelemesi denilmektedir (Karataş, 2015).

\subsection{Evren}

Bu çalışmanın evrenini çalışmanın yapıldığı tarih olan 2017 yılına kadar aktif öğrenme konusunu içeren Yüksek Öğretim Kurumu (YÖK)'nun internet sitesinde yayınlanmış tüm tezler oluşturmaktadır. Araştırmada başıı olarak ya da anahtar kelime olarak aktif öğrenme içeren tezler doküman olarak ele alınmış ve analizler bu doğrultuda yapılmıştır. Bu kapsamda 92 teze ulaşılmıştır. Tezlerin 81'inin tamamı internet sitesinde yayınlı iken 11'inin sadece özet bilgileri yer almaktadır. Özet bilgileri olan çalışmaların yazarlarına ulaşılmış ve çalışmaların tamamı elde edilmiştir. Çalışmada yer alan tezlerin, tez numaraları ekte sunulmuştur.

\subsection{Verilerin Kodlanması ve Çözümlenmesi}

Bu araştırmada elde edilen veriler doküman analizinde yer alan kodlama yöntemine göre kodlanmıştır. Sekiz alt başlık altında araştırmalara ait çalışma kimliği ve çalışma içeriği ile ilgili bilgiler yer almaktadır. Bunlar yayın yılı, yayın türü, araştırma yöntemleri, araştırma modelleri, örneklem türü, evren/örneklem/ çalışma grubu tanımlaması, araştırmaların değişkenleri ve veri toplama araçları olarak adlandırılmıştır. Tüm alt başılılardan oluşan bir form hazırlanmış ve 92 tez çalışması bu form kullanılarak incelenmiştir. Formdan elde edilen veriler SPSS 24.0 paket programına girilmiş ve her bir alt başlık için elde edilen veriler grafik, frekans ve yüzde tablolarına dönüştürülerek betimsel biçimde sunulmuştur.

\section{BULGULAR}

Çalışmada aktif öğrenme konusu ile ilgili YÖK'ün internet sitesinde yayımlanmış tüm tezler incelenmiştir. İncelenen toplam tez sayısı 92'dir. Araştırma kapsamından incelenen tezlerin yıllara göre dağılımı Şekil 1'de verilmiştir. 


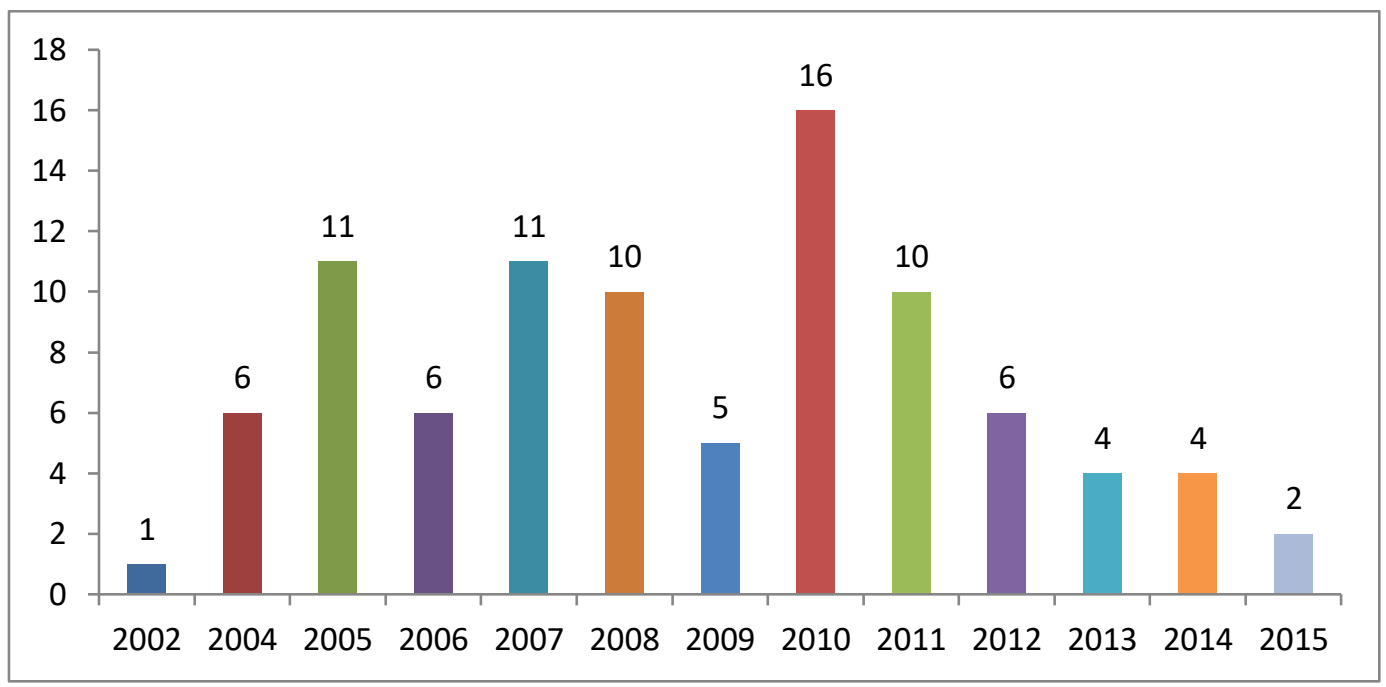

Şekil 1. Yıllara göre yazılmış tez sayıları

Şekil 1 incelendiğinde Türkiye'de aktif öğrenme konulu tez çalışmalarının 2002 yılında başladığı görülmektedir. Daha öncesinde herhangi bir çalışma bulunmamaktadır. Aktif öğrenme konusunu içeren tez çalışmalarının en çok 2010 yılında yapıldığı ve sonrasında çalışma sayısında düşüş olduğu gözlenmiştir.

Aktif öğrenme konusuna ilişkin yapılmış tezler yüksek lisans ve doktora olmak üzere iki farklı türdedir. Tezlerin türleri ve sayılarına ait bulgular Şekil 2'de verilmiştir.

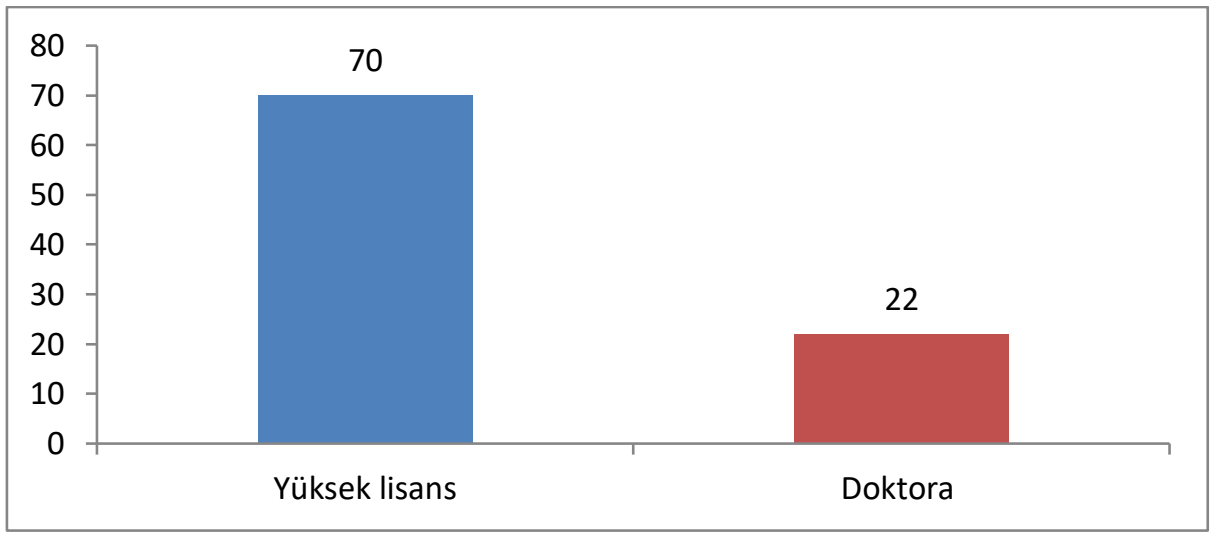

Şekil 2. Tez türlerine ait frekanslar

Şekil 2'de toplamda 92 adet olan tezlerin çoğunun (\%76) yüksek lisans tezi olduğu doktora tezlerinin ise daha az olduğu görülmektedir. Yıllara göre tezlerin türleri incelendiğinde ise doktora tezlerinin 2007 yılından sonra yazıldığı görülmüştür.

92 tez çalışması, araştırmanın temel aldığı yöntemler açısından incelenmiştir. Yöntemler nicel, nitel ve karma olarak üç sınıfa ayrılmıştır. Elde edilen bulgular Şekil 3'te gösterilmiştir. 


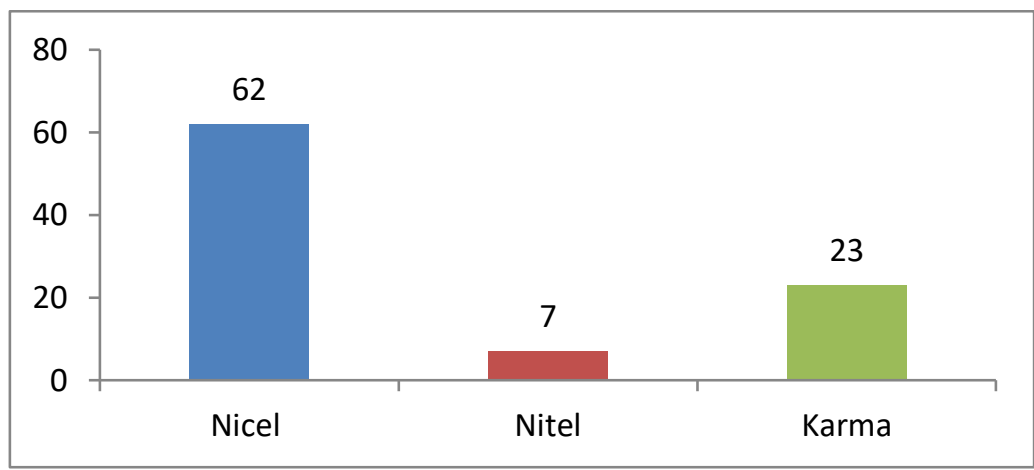

Şekil 3. Kullanılan araştırma yöntemlerine göre yazıımış tezlerin dağılımı

Incelenen tezlerin temel aldığı yöntemlere göre aktif öğrenme ile ilgili yazılmış tezlerin ağırıklı olarak nicel paradigmaya dayalı olduğu görülmektedir. Bu tezlerden nicel yöntemler ile yürütülenlerin sayısı 62, nitel paradigmaya göre yürütülenlerin sayısı 7'dir. 23 çalışmada hem nicel hem nitel paradigmanın desenlerinin kullanıldığı karma paradigma tercih edilmiştir. Bu bulgular ışığında aktif öğrenme ile ilgili yapılmış tezlerde nicel yöntemlerin daha ağırlıklı kullanıldığı görülürken nitel çalışmalarının ve karma paradigmanın daha az ele alındığı görülmektedir.

Çalışmada incelenen araştırmalar yöntem türlerinin dışında araştırma modelleri açısından da incelenmiştir. Nicel çalışmalar deneysel ve tarama modellerine göre, nitel çalışmalar durum çalışması, eylem araştırması, fenomenoloji ve etnografya modellerine göre sınıflandırılmışlardır. Karma çalışmalarda ise araştırma modelleri olarak açıklayıcı ve iç içe geçmiş modeller yer almaktadır. İncelenen tezlerde kullanılan araştırma modellerinin dağıımı Tablo 1'de gösterilmiştir.

Tablo 1. Yöntem türlerine göre çalışmalarda kullanılan araştırma modelleri sayısı

\begin{tabular}{llc}
\hline Yöntem türleri & Araştırma modelleri & Çalışma sayısı \\
\hline \multirow{2}{*}{ Nicel } & Deneysel & 57 \\
& Tarama & 5 \\
& Toplam & 62 \\
\hline \multirow{3}{*}{ Nitel } & Durum çalışması & 3 \\
& Eylem araştırması & 2 \\
& Fenomonolojik & 1 \\
& Etnografik & 1 \\
\multirow{2}{*}{ Karma } & Toplam & 7 \\
& Açıklayıcı & 12 \\
& İç içe geçmiş & 11 \\
& Toplam & 23 \\
\hline
\end{tabular}

Nicel paradigmaya dayalı yazılmış olan 62 tez çalışmasının 57'sinin deneysel model, 5'inin ise tarama modeli kullanılarak yapıldığı gözlenmiştir. 7 nitel çalışma içinde için de en sık kullanılan araştırma modeli 3 çalışma ile durum çalışmasıdır. Eylem araştırması 2, fenomonolojik ve etnografik model ise sadece 1'er tezde model olarak kullanılmıştır. 92 tez çalışması içinde karma yöntem kullanan toplam 23 tez vardır ve bunların 12'sinde açıklayıcı model 11'inde ise iç içe geçmiş model kullanılmıştır.

Çalışma kapsamında tezlerde kullanılan örnekleme türleri de incelenmiştir. Örnekleme türleri amaçlı, basit rasgele, kartopu, küme, tabakalı ve uygun örneklem yöntemleri başlı̆ı altında incelenmiştir. Incelenen tezlerin 23 tanesinde örnekleme türleri hakkında herhangi bir bilgi verilmemiştir. Geriye kalan 69 çalışmada kullanılan örnekleme türlerinin kullanım sayısına ait elde edilen sonuçlar Tablo 2'de verilmiştir. 
Tablo 2.Örnekleme türlerine göre belirtilen çalışma sayısı

\begin{tabular}{lc}
\hline Örnekleme türü & Çalışma sayısı \\
\hline Evren & 9 \\
Amaçıı & 23 \\
Basit rasgele & 22 \\
Uygun & 12 \\
Küme & 2 \\
Tabakalı & 1 \\
Toplam & 69 \\
\hline
\end{tabular}

Aktif öğrenme ile ilgili yapılan tez çalışmalarında 9 çalışma evren ile çalıştığını bildirmiştir. En fazla kullanılan örnekleme türü 23 çalışma ile amaçlı örneklemedir. Amaçı̈ı örneklemede çalışmanın amacına bağlı olarak bilgi açısından zengin durumlar seçilir (Büyüköztürk ve ark., 2013). 22 çalışmada basit rasgele, 12 çalışmada uygun, 2 çalışmada küme, 1 çalışmada ise tabakalı örnekleme yöntemi kullanılarak örneklemler belirlenmiştir.

Aktif öğrenme ile ilgili yazılan tezler ayrıca çalışılan grup (evren, örneklem ya da çalışma grubu) bakımından da incelenmiştir. Tezlerde, üzerinde çalışılan çalışma grubu, örneklem ya da evren ilköğretim, ortaöğretim ve lisans olarak 3 farklı kategoriye ayrılmıştır ve bu kategorilere ait kaç çalışma olduğu şekil 4'te verilmiştir.

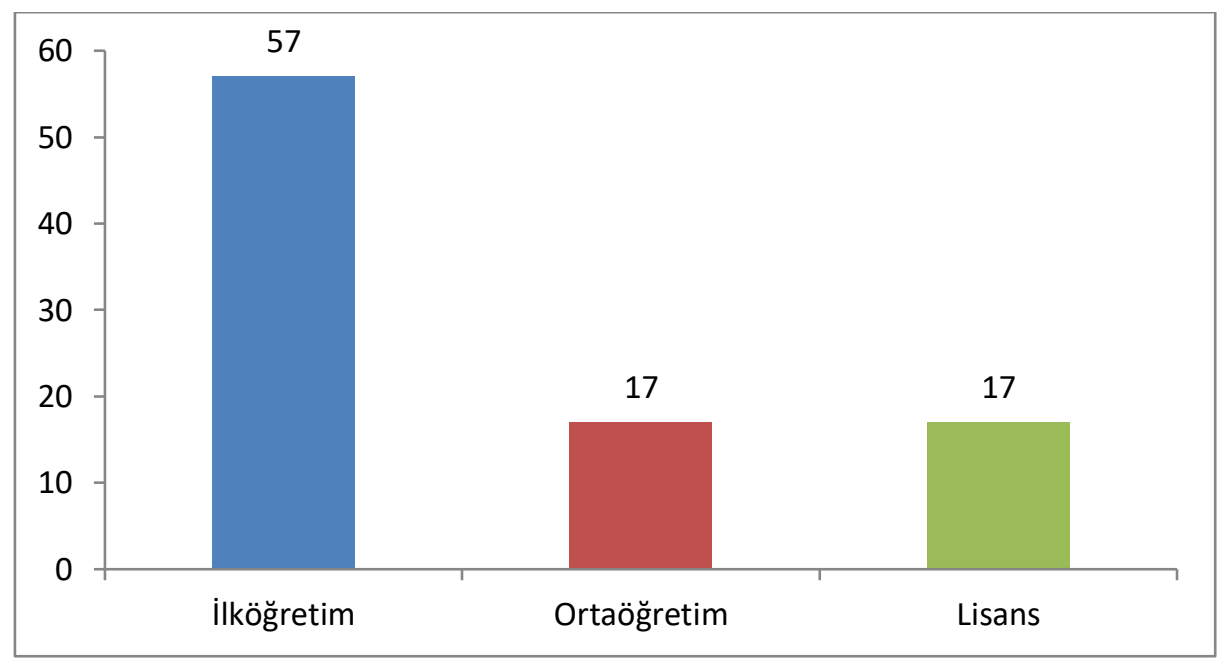

Şekil 4. Çalışma Grubu/Örneklem/Evren kategorilerine göre yapılmış tez sayıları

Şekil 4'e göre 92 tez çalışmasında en fazla ilköğretim öğrencileri ile çalışılmıştır. 17 çalışmada ortaöğretim öğrencileri, 17 çalışmada ise lisans öğrencileri incelenmiştir. İncelenen tez çalışmalarının 1'i döküman inceleme çalışması olduğu için örneklem ya da çalışma grubu bulunmamaktadır.

Bu çalışma kapsamında aktif öğrenme konulu tezlerin bir diğer inceleme alanı değişkenlerdir. Tezlerde araştırılan bağımlı ve bağımsız değişkenler ile ilgili bulgular Tablo 3'te yer almaktadır. 
Tablo 3. Tezlerde kullanılan değişken türlerine ait frekanslar

\begin{tabular}{llc}
\hline & Değişkenler & Kullanılan çalışma sayısı \\
\hline \multirow{3}{*}{ Bağımlı değişkenler } & Başarı & 46 \\
& Tutum & 29 \\
& Aktif öğrenme yöntemleri & 11 \\
& Motivasyon & 4 \\
& Kavram yanılgıları & 2 \\
\hline \multirow{3}{*}{ Bağımsız değişkenler } & Aktif öğrenme yöntemleri & 62 \\
& Kıdem & 8 \\
& Cinsiyet & 5 \\
& Yaş & 4
\end{tabular}

Tablo 3 incelendiğinde aktif öğrenme konusu ile yazılan tezlerin \%50'sinde başarı değişkeninin bağımlı değişken olarak kullanıldığı gözlenmiştir. Başarı değişkenini tutum, aktif öğrenme yöntemleri ve kavram yanılgıları değişkenleri izlemektedir. Kavram yanılgısı değişkeni sadece iki tezde bağımlı değişken olarak kullanılmıştır. Bu iki çalışma doktora tezi olmakla beraber kavram yanılgılarının aktif öğrenme yöntemlerini uygulama başarısı üzerindeki etkileri incelenmiştir. Tablo 3'te yer alan bilgilere göre aktif öğrenme konulu tezlerde daha çok aktif öğrenme yöntemlerinin diğer değişkenlere (başarı, tutum vs.) etkisi incelenmiştir. Tezlerde bağımsız değişken olarak kıdem, cinsiyet ve yaş kullanılan diğer değişkenlerdir.

Aktif öğrenme konulu tezler çalışmada kullanılan veri toplama araçları açısından incelenmiştir. Elde edilen bulgular Tablo 4'te yer almaktadır.

Tablo 4. Tezlerde kullanılan veri toplama araçlarına ait frekanslar

\begin{tabular}{lc}
\hline Veri toplama araçları & Kullanılan çalışma sayısı \\
\hline Başarı testi & 21 \\
Ölçek & 14 \\
Anket & 5 \\
Gözlem & 2 \\
Görüşme & 1 \\
Döküman & 1 \\
\hline Toplam & 44 \\
\hline Başarı testi + Ölçek & 19 \\
Başarı testi+ Anket & 6 \\
Görüşme+ Anket & 3 \\
Görüşme + Başarı testi & 3 \\
Görüşme + Ölçek & 1 \\
Gözlem + Başarı testi & 1 \\
Gözlem + Ölçek & 1 \\
\hline Toplam & 34 \\
\hline Başarı testi + Görüşme + Gözlem & 4 \\
Başarı testi + Görüşme + Ölçek & 3 \\
Başarı testi + Ölçek + Gözlem & 2 \\
Görüşme + Gözlem + Ölçek & 2 \\
\hline
\end{tabular}




\begin{tabular}{lc}
\hline Anket + Görüşme + Ölçek & 1 \\
Anket + Görüşme + Gözlem & 1 \\
Başarı testi + Gözlem + Döküman & 1 \\
Toplam & 14 \\
\hline Genel Toplam & 92
\end{tabular}

Tablo 4'e göre 44 çalışmada tek bir veri toplama aracı, 34 çalışmada iki farklı veri toplama aracı, 14 çalışmada ise üç farklı veri toplama aracı kullanılmıştır. Tek bir veri toplama aracı kullanılan çalışmalarda en fazla kullanılan veri toplama aracı başarı testidir. 21 çalışmada sadece başarı testi kullanılmıştır. 14 çalışmada sadece ölçek, 5 çalışmada sadece anket, 2 çalışmada sadece gözlem formu ve bir çalışmada sadece görüşme formu kullanılmıştır. Veri toplama aracı olarak dökümanları kullanan bir çalışma bulunmaktadır. İki farklı veri toplama aracının kullanıldığı çalışmalarda en fazla ölçek ve başarı testi bir arada kullanılmıştır. 19 çalışmada öğrencilerin başarısı ölçülmüş ve bu başarı ile farklı tutumları arasındaki ilişki incelenmiştir. 6 çalışmada anket ve başarı testi, 3 çalışmada görüşme formu ve anket, 3 çalışmada başarı testi ve görüşme formu, 1 çalışmada görüşme formu ve ölçek, 1 çalışmada gözlem ve başarı testi, 1 çalışmada ise gözlem formu ve ölçek beraber bir arada kullanılmıştır. Üç farklı veri toplama aracının kullanıldığı çalışmalardın toplam sayısı 14'tür ve en fazla başarı testi, görüşme formu ve gözlem bir arada kullanılmıştır. 3 çalışmada öğrencilerin başarıları ölçülmüş, herhangi bir tutum, özyeterlik, ilgi vb. başarıları arasındaki ilişki incelenmiş ve bulgular öğrencilerin görüşleri ile desteklenmiştir. 2 çalışmada başarı testi, ölçek ve gözlem formu, 2 çalışmada görüşme formu, gözlem ve ölçek, 1 çalışmada anketgörüşme formu ve ölçek, 1 çalışmada anket görüşme formu ve gözlem,1 çalışmada ise başarı testi, gözlem formu ve dökümanlar bir arada kullanıımıştır.

\section{SONUÇ, TARTIŞMA VE ÖNERILER}

Yapılan bu çalışmanın temel amacı özellikle son dönemlerde dünya genelinde ve ülkemizde eğitim sistemi içerisinde sıklıkla adı geçen ve üzerinde çalışmalar yürütülen aktif öğrenmeye ilişkin kapsamlı olarak yapılmış lisansüstü tezleri inceleyerek ülkemizdeki aktif öğrenme uygulamalarına ilişkin genel bir tablo oluşturmaktır. Çünkü Staton-Spicer ve Wulff (1984) "bir çalışma alanını tanımlamanın en uygun yolunun, o alanın araştırmalarını incelemek olduğunu, her disiplinin kendi ürünlerini periyodik olarak inceleme gereği ve zorunluluğu olduğunu" belirtmektedirler (Akt: Ozan ve Köse, 2014). Özellikle tezler öne sürülen fikir ve önermeleri içeren dokümanlardır ve bir alanda yapılacak araştırmaya belli bir bakış açısı kazandırırlar (Oruç ve Ulusoy, 2008). Bu amaç doğrultusunda elde edilen çalışmalar yayın yılı, yayın türü, araştırma yöntemleri, araştırma modelleri, örneklem türü, evren/örneklem/ çalışma grubu tanımlaması, araştırmaların değişkenleri ve veri toplama araçları değişkenleri açısından incelenmiştir.

Yayın yılı değişkeni açısından yapılan incelemede Türkiye'de aktif öğrenme konulu tez çalışmalarının 2002 yılında başladığı bilgisi elde edilmiştir. Aktif öğrenme konusunu içeren tez çalışmalarının en çok 2010 yılında yapıldığı ve sonrasında çalışma sayısında düşüş olduğu gözlenmiştir. Bu durumda özellikle 2010 yılında konuya olan ilginin arttığı ancak son yıllarda tez konusu olarak bu ilginin azalmış olduğunun gözlemlendiği söylenebilir. Toplamda 92 adet olan tezlerin çoğunun (\%76) yüksek lisans tezi olduğu doktora tezlerinin ise daha az olduğu görülmektedir. Doğru, Gençosman, Ataalkın ve Şeker (2012)'in fen ve teknoloji alanında yapılan tezlerin incelenmesine ilişkin yaptıkları çalışmada da yüksek lisans tezlerinden 23 tanesinin ve doktora tezlerinden 5 tanesinin aktif öğrenme konusunda olduğu ortaya konmuştur. Yıllara göre eğitim alanında yapılan tezlerin türleri incelendiğinde ise doktora tezlerinin 2007 yılından sonra yazıldığı görülmüştür. Bu durum genel olarak yapılan farklı çalışmalarda da (Şahin, GöğebakanYıldız ve Duman, 2011; Doğru, Gençosman, Ataalkın ve Şeker, 2012; Koç, 2016) doktora tezlerinde 2007 yılından sonra artış olduğunun gözlenmesi ile açıklanabilir. 
Incelenen tezlerin temel aldığı yöntemlere göre aktif öğrenme ile ilgili yapılmış tezlerde nicel yöntemlerin daha ağırlıklı kullanıldığı görülürken nitel çalışmalarının ve karma paradigmanın daha az ele alındığı görülmektedir. Türkiye'de yapılmış eğitim tezlerini inceleyen diğer pek çok çalışmada da (Hazır-Bıkmaz, Aksoy, Tatar ve Atak-Altınyüzük, 2013; Küçükoğlu ve Ozan, 2013; Yenilmez ve Sölpük, 2013; Ozan ve Köse, 2014; Koç, 2016) nicel yöntemlerin ağılıkta olduğu gözlemlenirken, Erdem (2011) yaptığı çalışmasında Türkiye'de eğitim alanında yapılan bilimsel araştırmaların büyük çoğunluğunun (\%82) nicel araştırma yöntemleri kullanılarak yapıldığını ortaya koymaktadır. Ayrıca Doğru, Gençosman, Ataalkın ve Şeker, (2012)'in yaptıkları çalışmada tüm alanlarda en az kullanılan araştırma modeli ise karma model olarak tespit edilmiştir.

Çalışmada incelenen araştırmalar yöntem türlerinin dışında araştırma modelleri açısından da incelenmiştir. Nicel paradigmaya dayalı yazıımış olan tez çalışmalarında ağıllıkı olarak deneysel modelin kullanıldığı gözlenmiştir. Oysa Şahin, Calp, Bulut ve Kuşdemir (2013) tarafından yapılan "Sınıf Öğretmenliği Eğitimi Bilim Dalında Yapılmış Lisansüstü Tezlerin Çeşitli Kriterlere Göre İncelenmesi" isimli çalışmada deneysel çalışmaların sayı olarak az olduğu tespit edilmiş ve bu durum gerekçesi deneysel yöntemlerin uzun sürmesi ve daha meşakkatli olmasının etkisi olabileceği şeklinde ifade edilmiştir.7 nitel çalışma içinde en sık kullanılan araştırma modeli 3 çalışma ile durum çalışmasıdır. 92 tez çalışması içinde karma yöntem kullanan toplam 23 tez vardır ve bunların 12'sinde açıklayıcı model 11 'inde iseiç içe geçmiş model kullanılmıştır. Nitel ve nicel çalışma verilerinin tek bir çalışmada ele alınarak farklı veri kaynaklarının birbirine dönüştürülüp doğrulandığı karma çalışmalar (Creswell, 2003) oldukça avantajı olmasına rağmen Ulutaş ve Ubuz, (2008) ve Çiltaş, Güler ve Sözbilir (2012) yaptıkları çalışmalarda Türkiye'de oldukça sınırlı sayıda karma çalışma yapıldığını belirtmişlerdir.

Çalışma kapsamında tezlerde kullanılan örnekleme türleri de incelenmiştir ve 9 çalışmada evren ile çalıştığını bildirilmiştir. En fazla kullanılan örnekleme türü 23 çalışma ile amaçı̈ı örneklemedir. 22 çalışmada basit rastgele, 12 çalışmada uygun, 2 çalışmada küme, 1 çalışmada ise tabakalı örnekleme yöntemi kullanılarak örneklemler belirlenmiştir. Incelenen tezlerde ağırlıklı olarak deneysel modelin kullanılmış olması ve deneysel çalışmalarda iç geçerliliğin yükseltilmesi için deneklerin seçiminde benzer kişisel özelliklere ve benzer geçmişe sahip kişilerden oluşmuş bir katılımcı havuzunun oluşturulması gerekliliği (Can, 2013:21) çalışmalarda örneklem seçiminde amaçlı örnekleme türünün çok olmasını açıklar niteliktedir. Ayrıca nicel çalışmalarda evren büyüklüğüne ulaşmaya çalışmak araştırma sonuçlarının genellenebilir olmasını engellediği gibi, emek, zaman ve para kaybına da neden olmaktadır (Özen ve Gül, 2007) ve evrenin özelliklerini yansıtan ve özelliklerin normal dağıldığı ya da normal dağıldığının kabul edildiği durumlarda rastgele seçilecek uygun boyutlu nispeten küçük bir örneklemin evreni temsil ettiği varsayılması (Yıldırım ve Şimşek, 2005) sonucu olarak araştırmalarda en çok kullanılan örnekleme yöntemi seçkisiz (rastgele, random) örnekleme olarak öne çıkmaktadır (Delice, 2010). Genel olarak aktif öğrenme ile ilgili yazılan tezler ayrıca çalışılan grup (evren, örneklem ya da çalışma grubu) bakımından da incelenmiştir ve elde edilen bilgilere göre aktif öğrenme konusu ile ilgili çalışmaların daha çok ilköğretim öğrencileri ile çalışıldığı görülmüştür. Bu durum özellikle 2004-2005 eğitim öğretim yılı itibariyle pilot olarak uygulanmaya konan ilköğretim programlarında aktif öğretim yöntemlerinin ağırlıklı olarak yer alması ile açıklanabilir. Bu çalışma kapsamında aktif öğrenme konulu tezlerin bir diğer inceleme alanı değişkenlerdir. Incelenen tezlerin \%50'sinde başarı değişkeninin bağımlı değişken olarak kullanıldığı gözlenmiştir. Bağımsız değişken olarak ise daha çok aktif öğrenme yöntemleri kullanılmıştır. Aktif öğrenme yöntemleri çok çeşitlidir ve bunlardan hangisinin öğrenci başarısını etkiyeceğini gözlemlemek adına farklı aktif öğrenme yöntemlerinin bağımsız değişken olarak kullanılması ve eğitim çalışmalarında bilişsel öğrenmelerin önemli sonucu olarak ortaya çıkan başarının bağımlı değişken olarak irdelenmesi beklenen bir sonuç olarak karşımıza çıkmaktadır.

Aktif öğrenme konulu tezler çalışmada kullanılan veri toplama araçları açısından incelenmiştir. 44 çalışmada tek bir veri toplama aracı, 34 çalışmada iki farklı veri toplama aracı, 14 çalışmada ise üç 
farklı veri toplama aracı kullanılmıştır. Tek bir veri toplama aracı kullanılan çalışmalarda en fazla kullanılan veri toplama aracı başarı testidir. Ulutaş ve Ubuz, (2008) ve Çiltaş, Güler ve Sözbilir (2012) yaptıkları çalışmalarda daveri toplama aracı olarak anket ve başarı testlerinin ön planda olduğu ve çalışmalarda \%73,5 oranında tek veri toplama aracının kullanıldığının ortaya çıkması göze çarpmaktadır. Iki farklı veri toplama aracının kullanıldığı çalışmalarda en fazla ölçek ve başarı testi bir arada kullanıımıştır. Üç farklı veri toplama aracının kullanıldığı çalışmaların toplam sayısı 14 'tür ve en fazla başarı testi, görüşme formu ve gözlem bir arada kullanılmıştır.

Çalışmadan elde edilen bulgular ışı̆̆ında aktif öğrenme konusundaki yüksek lisans ve doktora tez çalışmalarının arttırılması konusunda öğrenciler teşvik edilmeli ve bu alandaki boşluklar doldurulmalıdır. Ayrıca çalışmalar konusunda öğrenciler sadece nicel araştırma yöntemlerini kullanmakla kalmamalı, daha derinlemesine araştırmalar yapmak adına eylem araştırması, Fenomenolojik araştırma yapma konusunda yönlendirilmeli ve bilgilendirilmelidir. Aktif öğrenme son zamanlar artan önemi nedeniyle daha çok çalışııması ve üzerinde durulması gereken alandır. Bu açıdan ele alındığında sadece aktif öğrenme konusunda yapıımış tezler değil aynı zamanda bu konuda yapılmış makalelerde irdelenmelidir. Ayrıca yapılan bu çalışma doküman analizi modeli ile gerçekleşmiştir. Aktif öğrenme konulu tezler meta analiz yöntemi ile incelenerek alana yaptıkları katkının detaylı raporu elde edilebilir. Aktif öğrenme konusunda yazıımış tezlerin içerik açısından da incelenmesi araştırmacılar için sunulabilecek bir diğer öneridir.

\section{Kaynakça}

Adams, S. ve Burns, M. (1999). Connecting student learning and technology. Austin, TX: Southwest Educational Development Laboratory.

Aydede, M. N. (2006). Ilköğretim altıncı sınıf fen bilgisi dersinde aktif öğrenme yaklaşımını kullanmanın akademik başarı, tutum ve kalıııık üzerine etkisi. Yayımlanmamış Yüksek Lisans Tezi, Çukurova Üniversitesi, Sosyal Bilimler Enstitüsü, Adana

Aydede, M. N. ve Matyar, F. (2009). Fen bilgisi öğretiminde aktif öğrenme yaklaşımının bilişsel düzeyde öğrenci başarısına etkisi. Türk Fen Eğitimi Dergisi, 6(1), 115-127.

Aydede, M. N. ve Kesercioğlu, T. (2012). Aktif öğrenme uygulamalarının öğrencilerin kendi kendine öğrenme becerilerine etkisi. Hacettepe Üniversitesi Eğitim Fakültesi Dergisi, 43, 37-49.

Bonwell, C. C. ve Eison, J. A. (1991). Active learning: creating excitement in the classroom. (Rapor No. 1). ERIC Belgesi

Büyüköztürk, Ş., Çakmak, E., Akgün, Ö. E., Karadeniz, ş. ve Demirel, F. (2008). Bilimsel araştırma yöntemleri (Geliştirilmiş 2. baskı). Ankara: Pegem A Yayıncılık.

Bozyiğit, N, Onan, T. S, Özçınar, A. ve Erdem, A. (2014). An in-class project model: active learning and effective participation. Journal of Education and Future, 6, 15-24.

Can, A. (2013). SPSS ile bilimsel araştırma sürecinde nicel veri analizi. Ankara: Pegem A Yayıncılık.

Creswell, J. W. (2003). Research Design: qualitative, quantitative, and mixed methods approaches (2ndEd.). CA: Sage Publications.

Çelik, S, Şenocak, E, Bayrakçeken, S, Taşkesenligil, Y. ve Doymuş, K. (2005). Aktif öğrenme stratejileri üzerine bir derleme çalışması. Kazım Karabekir Eğitim Fakültesi Dergisi, 11, 155-185.

Çiltaş, A, Güler, G. ve Sözbilir, M. (2012). Türkiye'de matematik eğitimi araştırmaları: bir içerik analizi çalışması. Educational Sciences: Theory \& Practice, 12(1), 565-580.

Delice, A. (2010). Nicel araştırmalarda örneklem sorunu. Kuram ve Uygulamada Eğitim Bilimleri, 10(4), 1969-2018.

Doğru, M., Gençosman, T., Ataalkın, A. N. ve Şeker, F. (2012). Fen bilimleri eğitiminde çalışılan yüksek lisans ve doktora tezlerinin analizi. Türk Fen Eğitimi Dergisi, 9(1), 49-64. 
Erdem, D. (2011). Türkiye'de 2005-2006 yılları arasında yayımlanan eğitim bilimleri dergilerindeki makalelerin bazı özellikler açısından incelenmesi: betimsel bir analiz. Eğitimde ve Psikolojide Ölçme ve Değerlendirme Dergisi, 2(1), 140-147.

Fies, C. H. (2005). Classroom Response Systems: What do they add to an active learning environment. Yayımlanmamış doktora tezi, Texas Üniversitesi, Austin.

Hazır-Bıkmaz, F., Aksoy, E., Tatar, Ö. ve Atak-Altınyüzük, C. (2013). Eğitim programları ve öğretim alanında yapılan doktora tezlerine ait içerik çözümlemesi (1974-2009). Eğitim ve Bilim, 38(168), 288-303.

Kalem, S. ve Fer, S. (2003). Aktif öğrenme modeliyle oluşturulmuş öğrenme ortamının öğrenme, öğretme ve iletişim sürecine etkisi. Kuram ve Uygulamada Ĕgitim Bilimleri, 3(2). 433-461.

Karataş, Z. (2015). Sosyal bilimlerde nitel araştırma yöntemleri. Manevi Temelli Sosyal Hizmet Araştırmaları Dergisi, 1(1), 62-80.

Koç, C. (2011). Aktif öğrenmenin okuduğunu anlama ve eleştirel düşünme üzerindeki etkileri. CÜ Sosyal Bilimler Dergisi, 35(1), 28-37.

Koç, E. S. (2016). Türkiye'de ilköğretim programlarının değerlendirilmesine yönelik yapılan lisansüstü tezlerin incelenmesi. Abant izzet Baysal Üniversitesi Eğitim Fakültesi Dergisi, 16(1), 198216.

Küçükoğlu, A. ve Ozan, C. (2013). Sınıf öğretmenliği alanındaki lisansüstü tezlere yönelik bir içerik analizi, Uluslararası Avrasya Sosyal Bilimler Dergisi, 4(12),27-47.

Lamy, S. L. (2000) Teaching introductory international relations with cases and analytical exercises. In J. S. Lantis, L.M. Kuzma, and J. Boehrer (Ed) The New International Studies Classroom: Active Teaching, Active Learning. içinde (pp. 21 - 35). Boulder: Lynne Rienner

Lantis, J. S., Kille, K. J. ve Krain, M. (2010). The state of the active teaching and learning literature. In R. A. Denemark (Ed.), The international studies encyclopedia. İçinde. Chichester, West Sussex, England: Wiley-Blackwell.

Mentiş-Taş, A. (2006). Öğretmen eğitiminde aktif öğrenme. Gazi Üniversitesi Kırşehir Eğitim Fakültesi, 6(2), 177-184

Newmann, F. M. (1991). Linking restructuring to authentic student achievement. Phi Delta Kappan. 72(6), 458-463.

NRC (National Research Council) (1996). National science education standards, Washington, DC: National Academy Press

Oruç, Ş. ve Ulusoy, K. (2008). Sosyal bilgiler öğretimi alanında yapılan tez çalışmaları. Selçuk Üniversitesi Ahmet Keleşoğlu Eğitim Fakültesi Dergisi, 26, 121 -132.

Ozan, C. ve Köse, E. (2014). Eğitim programları ve öğretim alanındaki araştırma eğilimleri. Sakarya University Journal of Education, 4(1), 116-136.

Özen, Y. ve Gül, A (2007). Sosyal ve eğitim bilimleri araştırmalarında evren-örneklem sorunu. KKEFDI/JOKKEF, 15, 394-422.

Simelane, S. ve Dimpe, D.M. (2011). Clicker technology: The tool to promote active learning in the classroom. A. Méndez-Vilas (Ed). Education in a technological world: communicating current and emerging research and technological efforts, içinde. Formatex.

Sivan, A, Leung, A. W, Woon, C. ve Kember, D. (2010). An implementation of active learning and its effect on the quality of student learning. Innovations in Education \& Training International, 37(4), 381-389.

Şahin, M., Göğebakan-Yıldız, D. ve Duman, R. (2011). An evaluation of the theses on social studies education in Turkey. Journal of Social Studies Education Research, 2(2), 96-121.

Şahin, D., Calp, Ş., Bulut, P. ve Kuşdemir, Y. (2013). Sınıf öğretmenliği eğitimi bilim dalında yapılmış lisansüstü tezlerin çeşitli kriterlere göre incelenmesi. Zeitschrift für die Welt der Türken Journal of World of Turks, 5(3), 187-205. 
Taşpınar, M. (1998). Modüler öğretim yönteminin öğrenci başarısına etkisi. Ĕğitim ve Bilim, 22(108), 45-52.

Ulutaş, F. ve Ubuz, B. (2008). Research and trends in mathematics education: 2000 to 2006. Elementary Education Online, 7(3), 614-626.

Ün- Açıkgöz, K. (2014). Aktif öğrenme. İzmir: Eğitim Dünyası Yayınları.

Ünal, S. (1999). Aktif öğrenme, öğrenmeyi öğrenmek ve probleme dayalı öğrenme. M. Ü. Atatürk Eğitim Fakültesi Eğitim Bilimleri Dergisi, 11, 373-378.

Yenilmez, K. ve Sölpük, N. (2014). Matematik dersi öğretim programı ile ilgili tezlerinincelenmesi (2004-2013), Eğitim ve Öğretim Araştırmaları Dergisi, 3(2), 33-42.

Yıldırım, A. ve Şimşek, H. (2005). Sosyal bilimlerde nitel araştırma yöntemleri. Ankara: Seçkin Yayıncilık.

Wilke, R. R. (2003). The effect of active learning on student characteristics in human physiology course for nonmajors. Advence in Physiology Education, 27(4), 207- 223.

Zavrak, M. (2003). Lise kimya programında atomun yapısı ünitesinde aktif öğrenme yöntemlerinin uygulanması. Yayınlanmamış Yüksek Lisans Tezi, Dokuz Eylül Üniversitesi, Eğitim Bilimleri Enstitüsü Ortaöğretim Fen ve Matematik Alanları Eğitimi, İzmir. 


\section{Extended Summary}

Approaches in which the learner is in the center and undertakes the responsibility of learning herself/himself with the changing tendencies in learning has been becoming prominent. A tendency towards methods that help the students learn by experiencing in the scope of especially in class and non-class learning activities has been standing out. It can be said that active learning which has been attracting a great deal of attention in many countries recently and in which the student is in the center instead of being a passive observer is a learning method that the student takes the responsibility of learning herself/himself. Many studies performed in the literature (Newmann and Wehlage, 1991; Robson, 1998; Fies, 2005; Swank-Day, 2004; Aydede, 2006; Zavrak, 2003; Wilke, 2003; Cite: Aydede and Matyar, 2009; Aydede and Matyar, 2009) show that active learning improves the success, knowledge, attention and attitude of the student, thus making learning easier, meaningful and effective. Additionally, it has been seen that active learning has a positive effect on reading comprehension and critical thinking (Koç,2011), developing self-learning skill of the student (Aydede and Kesercioğlu, 2012), learning-teaching and communication process(Kalem and Fer, 2003). It is thought that more detailed researches should be performed on active learning practices which are getting more and more attention every day and should be dealt with more deeply in a way that it can be used in learning and teaching environments. When it is considered that the most detailed studies on this subject are postgraduate studies, defining a general frame related to what kind of studies were performed on active learning subject in postgraduate studies and what were addressed in these studies is seen as important. In the light of this aim, comprehensive postgraduate theses on active learning were studied in order to create a general overview as to how practices aiming active learning were practised in our country. With this aim, the study was figured in screening model and the data were analysed via document analysis method which provides the analysis of documents containing written information about events or phenomena researched. The population of this study is composed of all the theses published on Council of Higher Education (YÖK) website which include the subject of active learning. Theses having active learning as title or key word were examined and analyses were performed accordingly in the study. 92 theses were reached in this scope. While all of the 81 theses were published fully on the website, 11 theses had only abstracts. The writers of the studies with only abstracts were reached and full studies were acquired. The data obtained in this study were coded according to the coding method in the document analysis. The data related to work group identification and work content of the studies is present under 8 sub headings. These were referred as publish year, publish type, research methods, research models, sampling type, population/sampling study group specification, research variables and data collection tools. A form containing all of the sub headings was prepared and 92 theses were studied via this form. Data obtained with the form were entered into SPSS 24.0 packaged software and the data obtained for each sub heading were offered descriptively by being transformed into graph, frequency and percentage tables.

In the analysis performed according to publish year, it has been obtained that theses on active learning in Turkey started in 2002. It has been observed that theses on active learning were written in 2010 most and then there has been a decrease in their number. In this context it can be said that the interest in the subject increased especially in 2010 but recently it has been seen that there is a decrease in this interest as a thesis subject. It has been seen that most of the 92 theses in total (\%76) are postgraduate theses while PhD theses are less common. According to the methods which the theses studied are based on, it has been seen that quantitative methods are more common in the theses related to active learning while qualitative study and hybrid paradigm are used less. The studies which were analysed in our research were analysed also in terms of research models that are not their method types. It has been seen that empirical model was used more in the theses written based on quantitative paradigm. Among the 7 quantitative studies, the most used research model is case study by 3 studies. There are 23 theses using hybrid method among 92 theses and descriptive model was used in 12 of them and inter-penetrating model was 
used in 11 of them. Sampling types used in theses within the scope of our study were also handled and it has been reported that 9 studies worked with population. The most used sampling type is purposeful sampling by 23 studies. Samples were determined by using simple random sampling in 22 studies, convenience sampling in 12 studies, cluster sampling in 2 studies and stratified sampling method in 1 study. Theses related to active learning were studied also in terms of the group studied (population, sampling or study group) and according to the data obtained, it has been seen that studies related to active learning were performed with primary school students more commonly. Within the scope of this study, another study field of the theses on active learning is variables. In the $\% 50$ of the theses studied, it has been observed that success variable is dependent variable. However, active learning methods have been used more as independent variable. Theses on active learning have been studied in terms of data collection tools used in the study. Only one data collection tool was used in 44 studies, two different data collection tools were used in 34 studies and three different data collection tools were used in 14 studies.

In the light of the findings of the study, students should be encouraged to increase the postgraduate and PhD theses on active learning and the gaps in this field should be filled. Additionally, the students should not only use quantitative research methods but also should be directed and informed about action research and phenomenological research in order to perform studies in depth. Active learning is a field that should be studied and put importance more because of its recent increasing significance. With this context, not only theses on active learning should be studied but also articles on this subject. 
EK1

\begin{tabular}{|c|c|c|}
\hline \multicolumn{3}{|c|}{ Çalışmada Kullanılan Tezlerin YÖK Tez Numaraları } \\
\hline 111202 & 214348 & 280631 \\
\hline 113713 & 191129 & 280684 \\
\hline 131608 & 205423 & 280376 \\
\hline 130148 & 216288 & 290613 \\
\hline 127980 & 179558 & 328045 \\
\hline 128061 & 234432 & 313058 \\
\hline 130307 & 218905 & 308903 \\
\hline 145631 & 220284 & 322243 \\
\hline 148636 & 231696 & 317137 \\
\hline 145452 & 219572 & 330192 \\
\hline 145105 & 215786 & 330226 \\
\hline 145245 & 218909 & 354487 \\
\hline 145264 & 213218 & 339315 \\
\hline 204513 & 250913 & 331735 \\
\hline 162136 & 239325 & 330197 \\
\hline 162654 & 228372 & 332222 \\
\hline 159264 & 268454 & 345572 \\
\hline 159120 & 278382 & 370133 \\
\hline 159013 & 257341 & 368342 \\
\hline 161506 & 266572 & 376641 \\
\hline 160478 & 266573 & 375684 \\
\hline 162615 & 278080 & 394896 \\
\hline 197106 & 265528 & 418647 \\
\hline 205749 & 279563 & 392928 \\
\hline 191633 & 279596 & 418244 \\
\hline 189800 & 270095 & 439718 \\
\hline 241869 & 279672 & 443517 \\
\hline 214808 & 279504 & 439474 \\
\hline 212425 & 298566 & 474230 \\
\hline 208132 & 280654 & 469663 \\
\hline 209360 & 294150 & \\
\hline
\end{tabular}

